\title{
Chemokine gene expression in lung CD8 T cells correlates with protective immunity in mice immunized intra-nasally with Adenovirus-85A
}

\author{
Lian N Lee ${ }^{1 *}$, Dilair Baban², Edward O Ronan', Jiannis Ragoussis², Peter CL Beverley', Elma Z Tchilian
}

\begin{abstract}
Background: Immunization of BALB/C mice with a recombinant adenovirus expressing Mycobacterium tuberculosis (M. tuberculosis) antigen 85A (Ad85A) protects against aerosol challenge with M. tuberculosis only when it is administered intra-nasally (i.n.). Immunization with Ad85A induces a lung-resident population of activated CD8 T cells that is antigen dependent, highly activated and mediates protection by early inhibition of $M$. tuberculosis growth. In order to determine why the i.n. route is so effective compared to parenteral immunization, we used microarray analysis to compare gene expression profiles of pulmonary and splenic CD8 T cells after i.n. or intradermal (i.d.) immunization.
\end{abstract}

Method: Total RNA from CD8 T cells was isolated from lungs or spleens of mice immunized with Ad85A by the i.n. or i.d. route. The gene profiles generated from each condition were compared. Statistically significant $(p \leq 0.05)$ differentially expressed genes were analyzed to determine if they mapped to particular molecular functions, biological processes or pathways using Gene Ontology and Panther DB mapping tools.

Results: CD8 T cells from lungs of i.n. immunized mice expressed a large number of chemokines chemotactic for resting and activated T cells as well as activation and survival genes. Lung lymphocytes from i.n. immunized mice also express the chemokine receptor gene $C x c r 6$, which is thought to aid long-term retention of antigenresponding T cells in the lungs. Expression of CXCR6 on CD8 T cells was confirmed by flow cytometry.

Conclusions: Our microarray analysis represents the first ex vivo study comparing gene expression profiles of CD8 $T$ cells isolated from distinct sites after immunization with an adenoviral vector by different routes. It confirms earlier phenotypic data indicating that lung i.n. cells are more activated than lung i.d. CD8 T cells. The sustained expression of chemokines and activation genes enables CD8 T cells to remain in the lungs for extended periods after i.n. immunization. This may account for the early inhibition of $M$. tuberculosis growth observed in Ad85A i.n. immunized mice and explain the effectiveness of i.n. compared to parenteral immunization with this viral vector.

\section{Background}

It is becoming increasingly apparent that when $\mathrm{T}$ cells are essential for protective immunity the route of vaccine delivery may be critical [1-4]. Mice immunized intra-dermally (i.d.) or intra-muscularly (i.m.) with recombinant adenovirus expressing Mycobacterium tuberculosis (M. tuberculosis) antigen 85A (Ad85A) make a very strong splenic CD8 $\mathrm{T}$ cell response, but show no reduction in the lung mycobacterial burden

\footnotetext{
* Correspondence: lian.lee@ndm.ox.ac.uk

${ }^{1}$ Nuffield Department of Medicine, University of Oxford, The Peter Medawar Building for Pathogen Research, South Parks Road, Oxford OX1 3SY, UK Full list of author information is available at the end of the article
}

after pulmonary challenge with $M$. tuberculosis compared to naïve mice. In contrast, mice immunized intranasally (i.n.) with Ad85A make much weaker splenic responses but develop a very strong lung CD8 $\mathrm{T}$ cell response to antigen $85 \mathrm{~A}$ and are able to reduce significantly the mycobacterial burden after $M$. tuberculosis challenge $[2,5,6]$. Regardless of the route of delivery, immunization with Ad85A generates a predominantly $\mathrm{CD} 8 \mathrm{~T}$ cell response in BALB/c mice, characterized by production of IFN $\gamma$, TNF and some IL-2. We and others have shown that in this model the localization and continued presence of $85 \mathrm{~A}$-specific cells at the site of pathogen entry is dependent on the presence of antigen 
in the lungs and correlates with protection $[5,7,8]$. Furthermore, $M$. tuberculosis growth in the lungs is inhibited during the first 8 days after infection in Ad85A i.n. immunized mice. This is in contrast to mice immunized parenterally with BCG, in which the kinetics of $M$. tuberculosis growth are unchanged compared to naïve mice up to day 14 [5]. Thus it appears that the presence of activated effector $\mathrm{T}$ cells in the lungs plays a role in the protective immunity induced by Ad85A i.n. immunization. Nevertheless, these data do not satisfactorily explain why mice immunized i.d., which make a strong systemic immune response to $85 \mathrm{~A}$, fail to show any protection against pulmonary $M$. tuberculosis infection or dissemination of $M$. tuberculosis to the spleen.

We therefore sought to determine whether there are any differences in gene expression in the CD8 T cells induced by Ad85A i.d. or i.n. immunization that might explain the difference in protection. Microarray analysis was performed on RNA from lung and spleen CD8 T cells from Ad85A i.n. or i.d. immunized mice. The transcriptional profiles of lung CD8 T cells from Ad85A i.n. immunized mice show higher expression of chemokines, activation markers and tissue homing receptors, which may enable them to reside in the lung for extended periods.

\section{Methods}

\section{Animals and immunization}

All experiments were performed with 6-8 week old female BALB/c mice (Harlan Orlac, Blackthorn, UK), were approved by the animal use ethical committee of Oxford University and fully complied with the relevant Home Office guidelines. Mice were immunized with a recombinant replication deficient adenovirus serotype 5 containing the 85A antigen from $M$. tuberculosis (Ad85A) [5]. For intra-dermal (i.d.) immunization mice were anaesthetized and injected with $25 \mu \mathrm{l}$ in each ear, containing a total of $2 \times 10^{9}$ virus particles (v.p.) of Ad85A per mouse and for i.n. immunization allowed slowly to inhale $50 \mu \mathrm{l}$ of $2 \times 10^{9}$ v.p. of Ad85A.

\section{Enrichment of CD8 T cells from lung and spleen and RNA extraction}

Lungs were perfused with PBS, cut into small pieces and digested with $0.7 \mathrm{mg} / \mathrm{ml}$ collagenase type I (Sigma, Poole, UK) and $30 \mu \mathrm{g} / \mathrm{ml}$ DNase I (Sigma) for $45 \mathrm{~min}$ at $37^{\circ} \mathrm{C}$. Lung fragments were then crushed through a cell strainer using a $5 \mathrm{ml}$ syringe plunger, washed, layered over Lympholyte (Cederlane, Ontario, Canada) and centrifuged. Interface cells were washed and CD8 T cells selected by adding CD8 Microbeads (Miltenyi Biotec, Bisley, UK), followed by positive selection on MACS columns. The isolated cells were placed in Trizol and total RNA extracted using chloroform and isopropanol followed by cleanup on Qiagen RNeasy MinElute spin columns (Qiagen, Crawley, UK). RNA was quantitated and purity was determined on a Nanodrop (Thermo Scientific, Loughborough, UK). The spleens were passed through a cell strainer using a $5 \mathrm{ml}$ syringe plunger, then red blood cells were lysed using RBC lysis buffer (Qiagen). The cells were washed and CD8 T cells positively selected using CD8 Microbeads, followed by extraction of total RNA as described for the lung samples. For each immunization route separate pools of 7 lungs or spleens were made and subjected to microarray analysis.

\section{Microarray analysis}

Genome-wide gene expression analysis was performed using MouseWG6_v2 beadchips (Illumina, Little Chesterford, UK) containing 45,200 annotated transcripts. Briefly, total RNA was amplified and labeled with biotin during in vitro transcription, then hybridized to the array, washed, stained with Cy3-Streptavidin complex and subsequently scanned. QC and gene detection was performed using GenomeStudio (Illumina). For each condition, RNA samples obtained from 3 independent experiments were tested separately to generate triplicate sets of data per condition. The data files are available at the Gene Expression Omnibus data repository: GSE23713. The genes detected from each condition were compared against others to determine statistically significant $(\mathrm{p} \leq 0.05)$ fold changes in expression. The lists of differentially expressed genes and their corresponding fold change values were subsequently analyzed using Gene Ontology [9] and Panther DB websites [10] to determine whether the changes mapped to particular molecular functions, biological processes or pathways.

\section{Aerosol M. tuberculosis challenge}

Four weeks after the Ad85A immunization, mice were challenged by aerosol with M. tuberculosis (Erdman strain, kindly provided by Dr Amy Yang, CBER/FDA) using a modified Henderson apparatus [11]. Deposition in the lungs was measured $24 \mathrm{~h}$ after $M$. tuberculosis challenge and was $\sim 200 \mathrm{CFU}$ per lung. Mice were sacrificed at 6 weeks after M. tuberculosis challenge. Spleens and lungs were homogenized and the bacterial load was determined by plating 10 -fold serial dilutions of tissue homogenates on Middlebrook 7H11 agar plates (E \& O Laboratories Ltd, Bonnybridge, UK). Colonies were counted after 3-4 weeks of incubation at $37^{\circ} \mathrm{C}$ in $5 \% \mathrm{CO}_{2}$.

\section{Flow cytometry}

Lung cells were cultured in DMEM supplemented with $10 \%$ heat-inactivated FBS, L-glutamine, penicillin and streptomycin. Cells were stimulated with a mix of 3 
peptides (Peptide Protein Research Ltd, Fareham, UK) encoding dominant and subdominant CD8 and dominant CD4 epitopes of antigen 85A [5]. Each peptide was at a final concentration of $2 \mu \mathrm{g} / \mathrm{ml}$ during the stimulation. After 1 hour at $37^{\circ} \mathrm{C}$ Golgi Plug (BD Biosciences, Oxford, UK) was added according to the manufacturer's instructions and cells were incubated for an additional 5 hours before intracellular cytokine staining.

Cells were washed and incubated with CD16/CD32 $\mathrm{mAB}$ to block Fc binding. Subsequently the cells were stained for CD4 (RM4-5), IFN $\gamma$ (XMG1.2), IL-2 (JES65H4), TNF (MP6-XT22), Lag3 (C9B7W) and Ly 6A (D7) (eBioscience, Hatfield, UK), CXCR6 antibody (221002) (R\&D Systems, Abingdon, UK), and CD8 (536.7) (BD Bioscience). For intracellular cytokine staining, cells were stained using the BD Cytofix/Cytoperm kit according to the manufacturer's instructions. Cells were fixed with PBS $1 \%$ paraformaldehyde, run on a LSRII (BD Biosciences) and analyzed using FlowJo software (Tree Star Inc, Ashland, Oregon, USA).

\section{Detection of chemokines by ELISA}

Lung lymphocytes were isolated as described above and incubated in RPMI $+10 \%$ FCS at $37^{\circ} \mathrm{C}$ for 6 hours without stimulation. The supernatant was collected and stored at $-80^{\circ} \mathrm{C}$ until analysis. CXCL16 (R\&D Systems) ELISA and Multi-Analyte ELISArray for Mouse Common Chemokines (SABiosciences, Frederick, MD, USA) kits were employed.

\section{Results}

Immunization with Ad85A i.n. or i.d

In agreement with previous reports [2,5,6], mice immunized with Ad85A i.n. developed a strong 85A-specific $\mathrm{T}$ cell response in the lung and a much weaker splenic response, while Ad85A i.d. immunized mice make a stronger spleen and weaker lung response (Figure 1). Ad85A i.n. mice reduced the lung mycobacterial load by $\sim 1 \log$ compared to naïve mice (Figure $2 \mathrm{~A}$ ), a protective effect comparable to BCG $[5,12]$, while Ad85A i.d. immunization did not reduce the bacterial load either in the lungs or spleen (Figure 2B). The responses induced by Ad85A in BALB/c mice are dominated by CD8 T cells (Figure 1). In C57BL/6 mice Ad85A immunization induces a CD4 response and no consistent statistically significant protection against pulmonary $M$. tuberculosis challenge is obtained. However in BALB/c mice it has been demonstrated that antigen-specific CD8 $\mathrm{T}$ cells in the lung are critical for protection against pulmonary infection with $M$. tuberculosis in this immunization model $[7,13]$. Therefore we wished to determine if CD8 $\mathrm{T}$ cells from the lungs and spleens of BALB/c mice differed. Mice were immunized i.n. or i.d. with Ad85A and CD8 $\mathrm{T}$ cells isolated from the lungs (lung i.n. or i.d.) or spleens (spleen i.n. or i.d.) 3 weeks post-immunization, close to the peak of the cytokine response [5]. Purification by positive selection resulted in CD8 T cell populations which were $80-86 \%$ pure from lungs and $86-90 \%$ pure from spleens. Total RNA was prepared from cells isolated in 3 independent experiments, amplified and global genome analysis was performed using Illumina microarrays. The expression profiles of spleen and lung CD8 $\mathrm{T}$ cells were compared. Transcripts with $\geq 2$ fold difference in signal intensity with a p-value of $\leq 0.05$ were considered for further analysis, apart from the comparison between spleen i.n. and spleen i.d. where transcripts with $\geq 1.5$ fold difference were considered.

\section{Comparison of gene expression between lung i.n. and spleen i.d}

We compared the expression profiles of lung i.n. (protective regime) with spleen i.d. (non-protective regime) CD8 T cells. 550 transcripts were found to be differentially expressed (Additional file 1), with 186 transcripts more highly expressed by the lung i.n. sample and 364 transcripts by the spleen i.d. samples. Gene Ontology mapping of the 550 differentially expressed genes indicated that a large proportion were related to expression of extracellular proteins or involved in responses to extracellular stimuli or immune system processes (Figure 3A).

In agreement with this, when the list of differentially expressed genes was classified according to function using Panther analysis, 105 of the 550 differentially expressed transcripts were found to be involved in immune-related processes (Table 1). Of these 105 transcripts, 64 were more highly expressed in spleen i.d. samples, many of which were classified as related to either inflammation, complement- or ligand-mediated signaling processes, signal transduction or other host immune responses (Table 1). Additionally, higher levels of transcripts for antimicrobial molecules such as cathelicidin (Camp) (section XI Table 1) and lactotransferrin (Ltf) (section XII Table 1) were detected. Human cathelicidin has been reported to inactivate adenoviruses [14] and lactotransferrin to mediate entry of adenovirus subtype 5 virus into cells [15]. The only chemokine-related genes more highly expressed in spleen i.d. samples were Ccl24, along with its cognate receptor $\mathrm{Ccr} 3$. In addition to processes associated with immunity, the Panther program also predicted that many genes more highly expressed in spleen i.d. samples play a role in numerous and diverse non-immune associated processes such as blood circulation and gas exchange, blood clotting, porphyrin metabolism, sensory perception, proteolysis and cell structure and motility (data not shown).

In contrast, of the 41 genes more highly expressed in lung i.n. samples, 8 are chemokines, namely Xcl1, Cxcl1, 
A

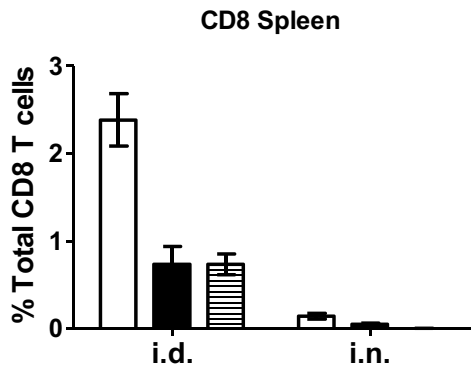

C

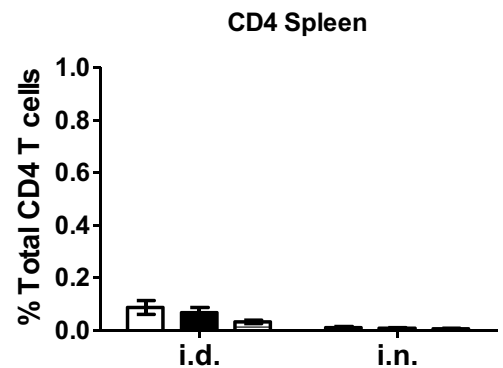

B

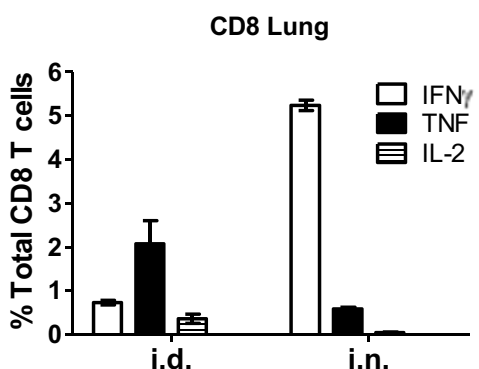

D

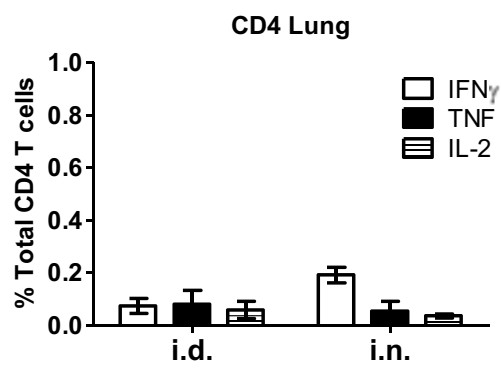

Figure 1 Cytokine responses of $\mathrm{T}$ cells to antigen 85A. BALB/C mice were immunized with Ad85A i.d. or i.n. Lung and splenic lymphocytes were isolated 3 weeks post-immunization and stimulated with the dominant CD4 and dominant and subdominant CD8 peptides. The percentage of cells expressing IFN $\gamma$, TNF and IL-2 in (A) splenic CD8, (B) lung CD8, (C) splenic CD4 and (D) lung CD4 T cells as determined by flow cytometry. The values shown are the mean \pm SEM from 3 mice per group and are representative of results obtained from at least 2 independent experiments.

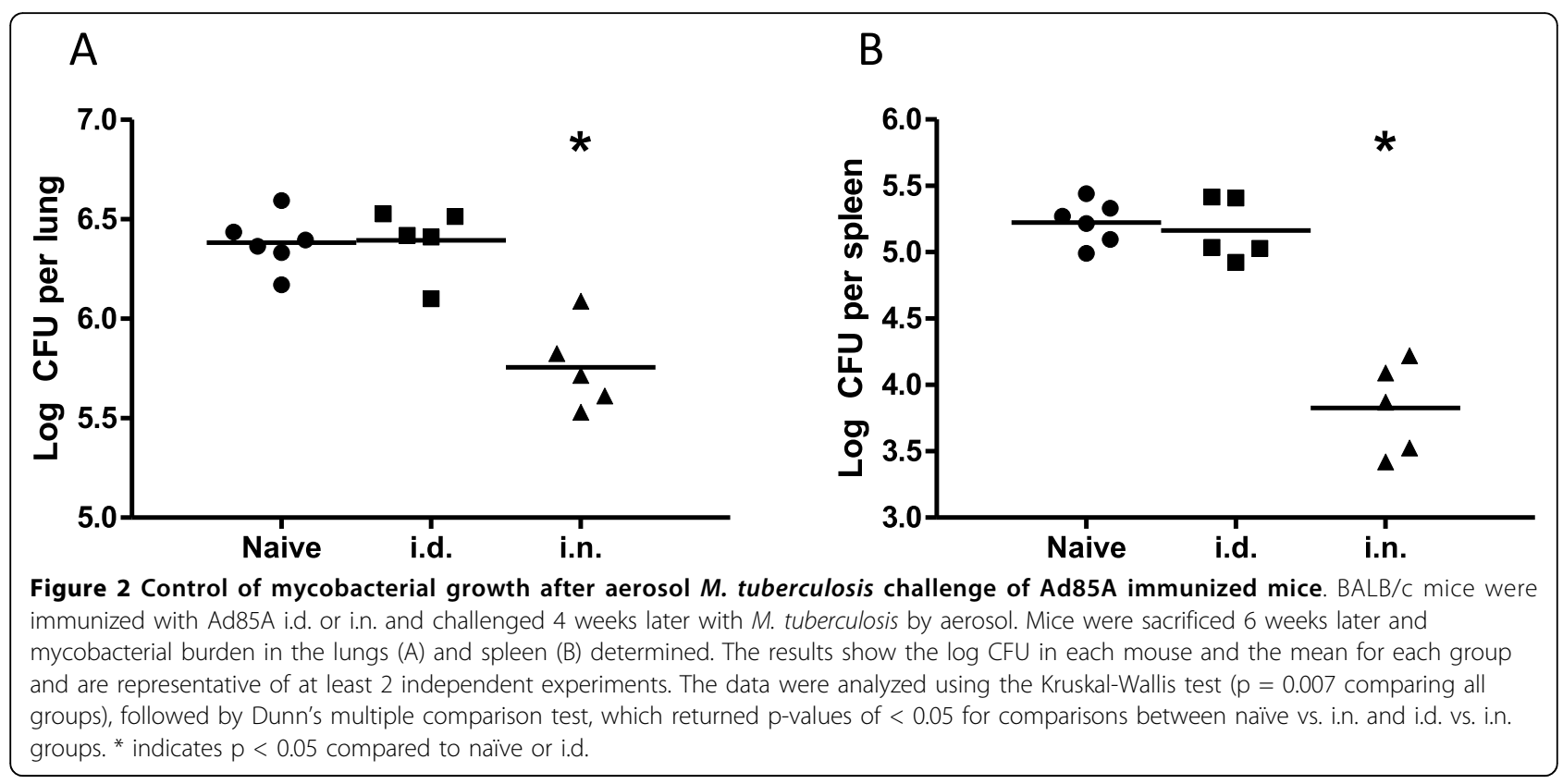



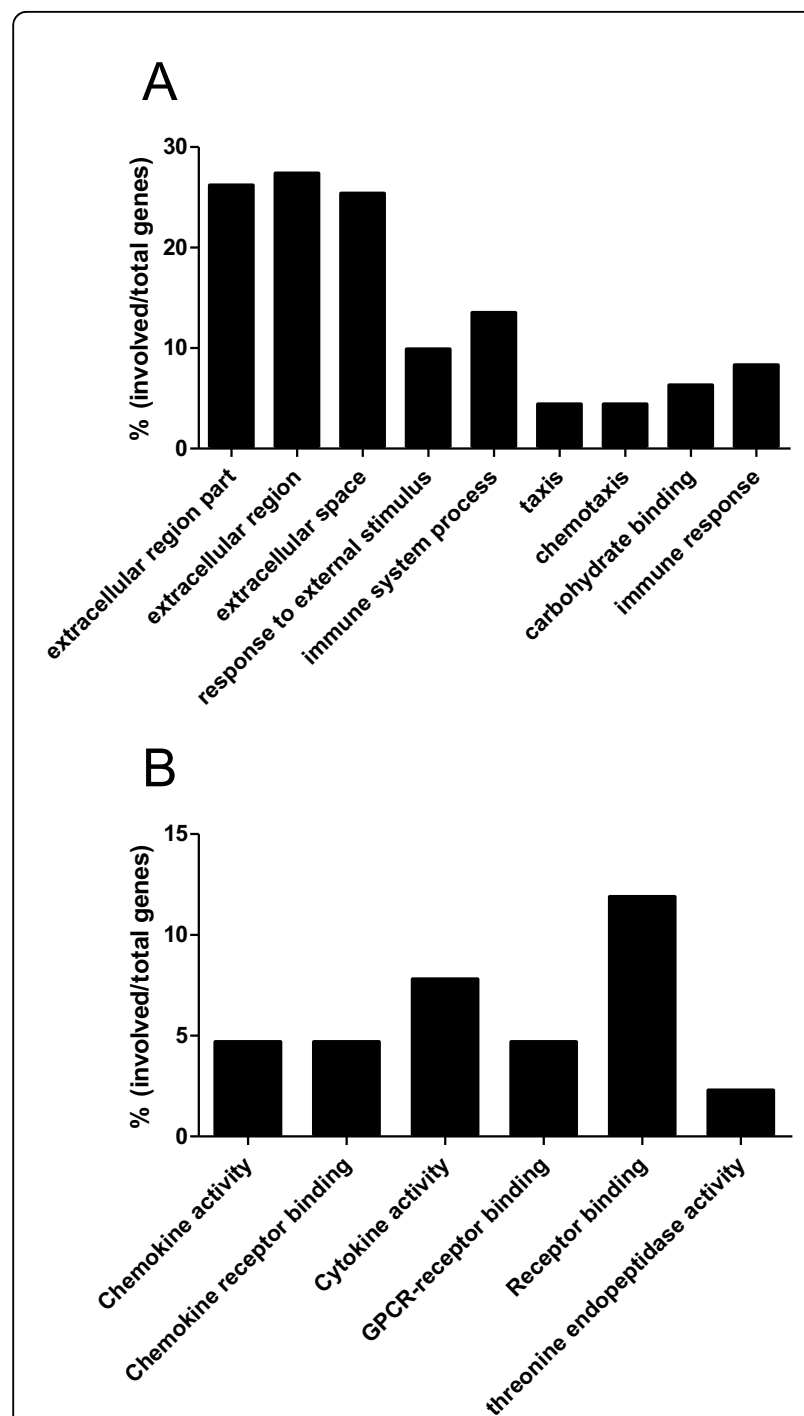

Figure 3 Gene Ontology analysis of differentially expressed genes in CD8 T cells. (A) Spleen i.d. vs lung i.n., based on 550 differentially expressed transcripts and (B) lung i.n. vs lung i.d. based on 245 differentially expressed transcripts ( $>2$ fold difference, $p<0.05$ ).

Cxcl2, Ccl1, Ccl2, Ccl12, Ccl7 and Ccl8 and a further three, Oas12, Oas2 and Gbp1, are interferon-stimulated genes (sections I and II Table 1). Chemokines such as Xcl1, Ccl1, Ccl2, Ccl7 and Ccl8 are responsible for recruitment of activated $\mathrm{T}$ cells into tissues (IUPHR database: http://www.iuphar-db.org/DATABASE/FamilyIntroductionForward?familyId=14). Because selection of genes in Panther is dependent on what has been curated, some genes that were differentially expressed and clearly related to immune processes but not classified by Panther, were added to Table 1 (section XII). Two other chemokine genes, $C x c l 12$ and $C x c l 13$, were preferentially expressed in lung i.n. samples (section XII Table 1), as was the $\mathrm{T}$ cell activation/memory marker
Ly6a. Genes involved in lymphocyte effector function such as Ifngr2 (IFN $\gamma$ receptor 2) and the TNF-stimulated gene TNFsf13b (BAFF) [16] were also upregulated in lung i.n. These data suggests that Ad85A i.n. immunization establishes an activation program in lung CD8 $T$ cells differing from that found in the spleen of Ad85A i.d. immunized mice.

It should be noted that some of the differences in gene expression shown in Table 1 are most likely due to contaminating cell types, which are a particular problem in the lung i.n. samples. For example, secretoglobin (Scgbla1) and surfactant associated protein D $(S p d)$ show high fold-differences in the comparison but these proteins are predominantly produced by pulmonary Clara cells [17] or type II cells [18] and not T cells. Not surprisingly, these genes do not show differences in expression between lung i.n. and lung i.d. samples (below), which presumably have approximately equal contamination with non-lymphoid lung cells.

\section{Comparison of gene expression between lung i.n. and lung i.d}

When lung i.n. (protective) were compared to lung i.d. (non-protective) CD8 T cells, we found a total of 245 differentially expressed genes (Additional file 2). Almost all the differentially expressed genes were more highly expressed in the lung i.n. samples. Gene Ontology analysis indicated that many of the highly expressed transcripts in the lung i.n. cells were related to immune processes (Figure $3 \mathrm{~B}$ ). Panther classification indicated that 86 of the 245 genes play a role in immune-related processes. Of these, 16 were classified as cytokine- and chemokine-mediated immunity and signaling genes, 11 as interferon-stimulated genes, 23 as $\mathrm{T}$ cell activation genes and 7 as apoptosis-related (Table 1). As before, a further 14 immunologically-related genes which were not curated by Panther were added to the table (section XII Table 1).

The lung i.n. sample expressed higher levels of the tissue-homing CC chemokines Ccl1, Ccl2, Ccl3, Ccl4, Ccl5, Ccl7, Ccl8 and CXC chemokines Xcl1, Cxcl2, Cxcl9 and Cxcl16, which are able to recruit resting and activated $\mathrm{T}$ cells as well as other immune cells. Cxcr6, which may aid in localization of activated $\mathrm{T}$ cells to non-lymphoid tissue [19-21], was also preferentially up-regulated in the lung i.n. samples. Flow cytometric analysis indicated that this was detectable on the surface of lung i.n. CD8 T cells but was present on very few CD8 $\mathrm{T}$ cells from lung i.d. immunized animals, confirming the differential expression detected by microarray analysis (Figure 4A). Similarly, increased expression of Lag3 protein was detected on the surface of a subset of lung i.n. CD8 T cells (Figure 4B). Measurement of chemokine production by ex vivo lung lymphocytes isolated from i.n. and 
Table 1 Differentially expressed host genes which mapped to immune related responses

\begin{tabular}{|c|c|c|c|c|}
\hline Annotation & Name & Accession & Fold D & rence \\
\hline I Cytokine and chemokine-mediated immunity and signalling & & & $\begin{array}{l}\text { lung i.n. vs } \\
\text { spleen i.d. }\end{array}$ & $\begin{array}{l}\text { lung i.n.vs } \\
\text { lung i.d. }\end{array}$ \\
\hline CD40 antigen & $C d 40$ & NM_170702.2 & & 3.0 \\
\hline Chemokine ( $\mathrm{C}$ motif) ligand 1 & $x \mathrm{Cl} / 1$ & NM_008510.1 & 4.0 & 8.0 \\
\hline Chemokine ( $\mathrm{C}-\mathrm{C}$ motif) ligand 1 & $\mathrm{CCl1}$ & NM_011329.1 & 9.7 & 6.7 \\
\hline Chemokine (C-C motif) ligand 2 & $\mathrm{Ccl} 2$ & NM_011333.1 & 3.2 & 2.2 \\
\hline Chemokine (C-C motif) ligand 3 & $\mathrm{CCl}$ & NM_011337.1 & & 4.3 \\
\hline Chemokine (C-C motif) ligand 4 & $\mathrm{Ccl} 4$ & NM_013652.1 & & 7.4 \\
\hline Chemokine ( $\mathrm{C}-\mathrm{C}$ motif) ligand 5 & $\mathrm{CCl} 5$ & NM_013653.1 & & 3.4 \\
\hline Chemokine (C-C motif) ligand 7 & $\mathrm{Ccl} 7$ & NM_013654 & 17.9 & 6.9 \\
\hline Chemokine ( $\mathrm{C}-\mathrm{C}$ motif) ligand 8 & $\mathrm{Ccl} 8$ & NM_021443.1 & 10.7 & 4.3 \\
\hline Chemokine (C-C motif) ligand 12 & $\mathrm{Cc} 112$ & NM_011331 & 2.7 & \\
\hline Chemokine (C-C motif) ligand 24 & $\mathrm{Cc} / 24$ & NM_019577.2 & -4.3 & \\
\hline Chemokine (C-X-C motif) ligand 1 & Cxcl1 & NM_008176.1 & 2.9 & \\
\hline Chemokine (C-X-C motif) ligand 2 & $\mathrm{CxCl} 2$ & NM_009140 & 2.4 & \\
\hline Chemokine (C-X-C motif) ligand 9 & CxC19 & NM_008599 & & 12.6 \\
\hline Chemokine (C-C motif) receptor 3 & $\mathrm{Ccr3}$ & NM_009914.2 & -2.1 & \\
\hline Chemokine (C-X-C motif) receptor 6 & Cxcr6 & NM_030712.1 & & 5.3 \\
\hline Colony stimulating factor 1 (macrophage) & Csfi & NM_0 07778.1 & 2.1 & \\
\hline Colony stimulating factor 3 receptor (granulocyte) & Csf3r & NM_007782.1 & -2.1 & \\
\hline Cytokine inducible $\mathrm{SH}$-containing protein & Cish & NM_009895.2 & 4.7 & 4.5 \\
\hline Interferon gamma & Ifng & NM_008337.1 & & 5.2 \\
\hline Interferon gamma receptor 2 & Ifngr2 & NM_008338.2 & 3.2 & \\
\hline Interleukin 18 & 1118 & NM_008360.1 & -4.3 & \\
\hline Lymphocyte-activation gene 3 & $\operatorname{Lag} 3$ & NM_008479.1 & 2.8 & 5.0 \\
\hline Protein tyrosine phosphatase, non-receptor type 6 & Hcph & NM_013545.1 & & 2.0 \\
\hline Signal-regulatory protein alpha & Ptp4a3 & NM_008975.2 & -2.1 & \\
\hline Transferrin & Trf & NM_133977.1 & -8.8 & \\
\hline Tumor necrosis factor & Tnf & NM_013693 & & 2.6 \\
\hline
\end{tabular}

\section{Inflammation mediated pathway}

\begin{tabular}{llll}
\hline Cyclin-dependent kinase inhibitor 1A (P21) & Cdkn1a & NM_007669.2 & 2.2 \\
\hline Gardner-Rasheed feline sarcoma viral (Fgr) oncogene homolog & Fgr & NM_010208 & -3.5 \\
\hline Integrin alpha 9 & Itga9 & NM_133721.1 & -3.0 \\
\hline Procollagen, type XIV, alpha 1 & Col14a1 & AK052963 & -3.4 \\
\hline Prostaglandin-endoperoxide synthase 1 & Ptgs1 & NM_008969.1 & -7.0 \\
\hline Vav2 oncogene & Vav2 & NM_009500.1 & -3.7 \\
\hline
\end{tabular}

\section{Interferon-stimulated genes}

\begin{tabular}{|c|c|c|c|c|}
\hline 2'-5' oligoadenylate synthetase-like 2 & Oas/2 & NM_011854.1 & 4.0 & 3.3 \\
\hline 2'-5' oligoadenylate synthetase $1 \mathrm{G}$ & Oasig & NM_011852.2 & & 3.2 \\
\hline Guanylate nucleotide binding protein 1 & Gbpl & NM_010259.1 & 2.2 & 5.5 \\
\hline Guanylate nucleotide binding protein 2 & Gbp2 & NM_010260.1 & & 4.4 \\
\hline Guanylate nucleotide binding protein 4 & Gbp4 & NM_018734.2 & & 3.2 \\
\hline Interferon activated gene 202B & Ifi202b & NM_008327.1 & & 2.4 \\
\hline Interferon-induced protein with tetratricopeptide repeats 2 & lfit2 & NM_008332.2 & & 2.0 \\
\hline Interferon-induced protein with tetratricopeptide repeats 3 & Ifit3 & NM_010501.1 & & 3.9 \\
\hline Interferon regulatory factor 8 & $|c s b p|$ & NM_008320.2 & & 3.2 \\
\hline
\end{tabular}


Table 1 Differentially expressed host genes which mapped to immune related responses (Continued)

\begin{tabular}{|c|c|c|c|c|}
\hline Signal transducer and activator of transcription 1 & Stat1 & NM_009283 & & 3.0 \\
\hline SLAM family member 8 & Slamf8 & XM_129596.2 & & 5.0 \\
\hline \multicolumn{5}{|l|}{ IV T cell activation } \\
\hline Beta-2 microglobulin & $B 2 m$ & NM_009735.2 & & 2.3 \\
\hline Cathepsin S & Ctss & NM_021281.1 & & 3.0 \\
\hline $\begin{array}{l}\text { CD74 antigen (invariant polypeptide of major histocompatibility complex, } \\
\text { class II antigen-associated) }\end{array}$ & li & $\mathrm{BC} 003476$ & & 5.6 \\
\hline CD86 antigen & $\mathrm{Cd} 86$ & NM_019388.2 & -2.3 & 2.5 \\
\hline CD274 antigen & Pdcd1lg1 & NM_021893.2 & 2.5 & 3.8 \\
\hline Cytotoxic T-lymphocyte-associated protein 4 & Ctla4 & NM_009843.2 & & 3.9 \\
\hline Histocompatibility 2, Q region locus 6 & $\mathrm{H} 2-\mathrm{Q} 6$ & NM_207648 & & 3.0 \\
\hline Interferon gamma inducible protein 30 & Ifi30 & NM_023065.2 & & 2.5 \\
\hline Histocompatibility 2, class II antigen A, beta 1 & $H 2-A b 1$ & NM_207105.1 & & 7.7 \\
\hline Histocompatibility 2, D region locus 1 & H2-D1 & NM_010380.2 & & 3.0 \\
\hline Histocompatibility 2, class II, locus Dma & H2-DMa & NM_010386 & & 3.9 \\
\hline Histocompatibility 2, class II, locus Mb1 & $H 2-D M b 1$ & NM_010387.2 & & 5.8 \\
\hline Histocompatibility 2, class II, locus Mb2 & $\mathrm{H} 2-\mathrm{DMb} 2$ & NM_010388 & & 5.5 \\
\hline Histocompatibility 2, class II antigen E alpha & $\mathrm{H} 2-\mathrm{Ea}$ & NM_010381.2 & & 6.5 \\
\hline Histocompatibility 2, class II antigen E beta & H2-Eb1 & NM_010382.1 & & 7.9 \\
\hline Histocompatibility 2, K1, K region & $\mathrm{H} 2-\mathrm{K} 1$ & NM_001001892.1 & & 3.0 \\
\hline Histocompatibility 2, M region locus 3 & $\mathrm{H} 2-\mathrm{M3}$ & NM_013819.1 & & 2.6 \\
\hline Histocompatibility 2, Q region locus 2 & $\mathrm{H} 2-\mathrm{Q} 2$ & NM_010392.2 & & 2.7 \\
\hline Histocompatibility 2, Q region locus 5 & $\mathrm{H} 2-\mathrm{Q} 5$ & NM_010393.1 & & 2.9 \\
\hline Histocompatibility 2, T region locus 10 & H2-T10 & NM_010395.5 & & 2.5 \\
\hline Histocompatibility 2, T region locus 23 & H2-T23 & NM_010398.1 & & 2.9 \\
\hline Histocompatibility 2, T region locus 9 & H2-T9 & NM_010399 & & 3.1 \\
\hline Peroxiredoxin 5 & $\operatorname{Prd} \times 5$ & NM_012021 & & 2.2 \\
\hline \multicolumn{5}{|l|}{ V Other ligand-mediated signalling } \\
\hline Calcitonin/calcitonin-related polypeptide, alpha & Calca & NM_007587 & 2.0 & \\
\hline E2F transcription factor 2 & $E 2 f 2$ & NM_177733.2 & -3.4 & \\
\hline Endothelin 1 & Edn1 & NM_010104.2 & 2.1 & \\
\hline Endothelial differentiation, sphingolipid G-protein-coupled receptor, 5 & Edg5 & NM_010333 & & 2.1 \\
\hline FMS-like tyrosine kinase 1 & Flt1 & NM_010228.2 & 3.9 & \\
\hline Granulin & Grn & NM_008175.2 & & 2.8 \\
\hline Mannose-6-phosphate receptor, cation dependent & M6pr & NM_010749.4 & & 2.2 \\
\hline Paired-Ig-like receptor A1 & Piral & NM_011087.1 & -2.1 & \\
\hline Paired-lg-like receptor A11 & Pira11 & NM_011088.1 & -2.1 & \\
\hline Paired-lg-like receptor $\mathrm{A} 3$ & Pira3 & NM_011090.1 & -3.8 & \\
\hline Paired-Ig-like receptor A4 & Pira4 & NM_011091.1 & -2.4 & \\
\hline Peroxisome proliferator activated receptor gamma & Pparg & NM_011146.1 & -2.7 & \\
\hline Pre-B-cell colony-enhancing factor 1 & Pbef1 & NM_021524.1 & & 2.7 \\
\hline Secretoglobin, family $1 \mathrm{~A}$, member 1 (uteroglobin) & Scgbla1 & NM_011681.1 & 40.0 & \\
\hline Solute carrier family 1 (glial high affinity glutamate transporter), member 3 & Slcla3 & NM_148938.2 & -2.5 & \\
\hline Spermine oxidase & Smox & NM_145533.1 & -2.7 & \\
\hline Vascular endothelial growth factor $\mathrm{A}$ & Vegfa & NM_009505.2 & 2.5 & \\
\hline
\end{tabular}


Table 1 Differentially expressed host genes which mapped to immune related responses (Continued)

\begin{tabular}{|c|c|c|c|c|}
\hline \multicolumn{5}{|l|}{ VI Complement-mediated } \\
\hline Complement component 1, q subcomponent, alpha polypeptide & $\mathrm{Clqa}$ & NM_007572 & -3.6 & \\
\hline Complement component 1, q subcomponent, beta polypeptide & $C 19 b$ & NM_009777.1 & -4.5 & 3.8 \\
\hline Complement component 1, q subcomponent, $\mathrm{C}$ chain & Clag & NM_0 07574.1 & -4.3 & \\
\hline Complement component 2 (within $\mathrm{H}-2 \mathrm{~S}$ ) & C2 & NM_013484.1 & -3.3 & \\
\hline Complement component 3 & C3 & NM_009778.1 & & 4.2 \\
\hline Complement component 4A (Rodgers blood group) & SIp & NM_011413 & 2.3 & \\
\hline Complement component 6 & C6 & NM_016704.1 & -2.6 & \\
\hline Complement factor B & $\mathrm{H} 2-\mathrm{Bf}$ & NM_008198.1 & 11.5 & 6.5 \\
\hline Complement factor properdin & $P f C$ & XM_135820.3 & -10.3 & \\
\hline Four and a half LIM domains 1 & Fh/1 & NM_010211.1 & 2.3 & \\
\hline \multicolumn{5}{|l|}{ VII Apoptosis } \\
\hline B-cell leukemia/lymphoma 2 related protein A1b & Bcl2a1b & NM_0 07534 & & 2.5 \\
\hline B-cell leukemia/lymphoma 2 related protein A1d & Bcl2ald & NM_007536 & & 2.7 \\
\hline Caspase 1 & Casp1 & NM_009807.1 & & 4.0 \\
\hline Caspase 4, apoptosis-related cysteine peptidase & Casp4 & NM_007609.1 & & 2.4 \\
\hline Epithelial membrane protein 3 & Emp3 & NM_010129.1 & & 2.3 \\
\hline Lectin, galactose binding, soluble 1 & Lgals1 & NM_008495.1 & & 4.0 \\
\hline Thioredoxin 1 & $T \times n 1$ & NM_011660.3 & & 2.1 \\
\hline \multicolumn{5}{|l|}{ VIII Signal transduction } \\
\hline AXL receptor tyrosine kinase & $A \times l$ & NM_009465.2 & -6.4 & \\
\hline C-mer proto-oncogene tyrosine kinase & Mertk & NM_008587 & -3.7 & \\
\hline C-type lectin domain family 4 , member a1 & BC049354 & XM_194289.2 & -3.0 & \\
\hline C-type lectin domain family 4 , member b1 & Clec $4 b 1$ & NM_027218.1 & -3.9 & \\
\hline C-type lectin domain family 4 , member a3 & $\mathrm{Clec} 4 \mathrm{a}_{3}$ & NM_153197.3 & -2.1 & \\
\hline CD63 antigen & Cd63 & NM_007653.1 & 3.3 & \\
\hline CD81 antigen & $\mathrm{Cd} 81$ & NM_133655.1 & -4.6 & \\
\hline CD93 antigen & Clar1 & NM_010740.1 & 3.7 & \\
\hline CD207 antigen & Cd207 & NM_144943.2 & -2.2 & \\
\hline Chemokine (C-X-C motif) ligand 15 & Cxcl15 & NM_011339.1 & 5.0 & \\
\hline Colony stimulating factor 1 receptor & Csfir & NM_007779.1 & -9.5 & \\
\hline Integrin beta 5 & $\operatorname{ltg} 65$ & NM_010580 & -3.4 & \\
\hline Neutrophilic granule protein & Ngp & NM_008694.1 & -8.9 & \\
\hline Plasminogen activator, urokinase & Plau & NM_008873.2 & 2.2 & \\
\hline S100 calcium binding protein A9 (calgranulin B) & $5100 a 9$ & NM_009114.1 & -4.2 & \\
\hline Thrombomodulin & Thbd & NM_009378.1 & 4.6 & \\
\hline \multicolumn{5}{|l|}{ IX Other cell communication } \\
\hline Cadherin 1 & Cdh1 & NM_009864.1 & 4.8 & 3.2 \\
\hline Hematological and neurological expressed sequence 1 & $\mathrm{Hnl}$ & NM_008258.1 & & 2.3 \\
\hline Intercellular adhesion molecule & Icam1 & NM_010493.2 & & 2.3 \\
\hline Lectin, galactoside-binding, soluble, 3 binding protein & Lgals3bp & NM_011150.1 & & 4.0 \\
\hline Proteolipid protein 2 & Plp2 & NM_019755.2 & & 2.5 \\
\hline Purine-nucleoside phosphorylase & Pnp & NM_013632.2 & & 3.2 \\
\hline
\end{tabular}


Table 1 Differentially expressed host genes which mapped to immune related responses (Continued)

\begin{tabular}{|c|c|c|c|c|}
\hline $\mathrm{X}$ Natural killer cell-mediated immunity & & & & \\
\hline Fc fragment of IgG, low affinity IIla, receptor & $\mathrm{Fcrl3}$ & NM_144559.1 & & 3.8 \\
\hline Killer cell lectin-like receptor subfamily $C$, member 1 & Klrc1 & NM_010652 & & 3.8 \\
\hline Killer cell lectin-like receptor subfamily K, member 1 & Klrk1 & NM_033078.2 & & 2.0 \\
\hline Natural killer cell group 7 sequence & Nkg7 & NM_024253.3 & & 3.7 \\
\hline \multicolumn{5}{|l|}{ XI Other host immune responses } \\
\hline Allograft inflammatory factor 1 & Aif1 & NM_019467.2 & -2.8 & 2.7 \\
\hline ATP-binding cassette, sub-family C (CFTR/MRP), member 3 & Abcc3 & XM_358306.1 & -10.6 & \\
\hline Carboxylesterase 3 & Ces3 & NM_053200.1 & 2.9 & \\
\hline Catalase & Cat & NM_009804.1 & -2.3 & \\
\hline Cathelicidin antimicrobial peptide & Camp & NM_009921.1 & -18.3 & \\
\hline Cathepsin E & Ctse & NM_007799 & -2.3 & \\
\hline CD59a antigen & Cd59a & NM_0 07652.2 & -3.0 & \\
\hline CD93 antigen & Clarl & NM_010740.1 & 3.7 & \\
\hline CD163 antigen & Cd163 & NM_053094.1 & -10.1 & \\
\hline CD244 natural killer cell receptor 2B4 & $\mathrm{Cd} 244$ & NM_018729 & -3.3 & \\
\hline Coagulation factor $X$ & $F 10$ & NM_0 07972.2 & 2.6 & \\
\hline Fc receptor, IgG, alpha chain transporter & Fcgrt & NM_010189.1 & -4.8 & \\
\hline Glutathione peroxidase 1 & Gpx1 & NM_008160.1 & -2.7 & \\
\hline Glutathione peroxidase 3 & Gpx3 & NM_008161.1 & -2.0 & \\
\hline Glutathione S-transferase, mu 2 & Gstm2 & NM_0 08183.2 & 5.0 & \\
\hline Glutathione S-transferase omega 1 & Gsto1 & NM_010362.1 & -2.1 & \\
\hline Guanine nucleotide binding protein (G protein), gamma 2 subunit & Gng2 & NM_010315.2 & & 2.9 \\
\hline Guanine nucleotide binding protein (G protein), gamma 10 & Gng10 & NM_025277 & & 2.4 \\
\hline Hemochromatosis & $\mathrm{Hfe}$ & NM_010424.2 & -5.3 & \\
\hline Immunoresponsive gene 1 & $\operatorname{lrg} 1$ & XM_127883 & 2.8 & \\
\hline Interferon, alpha-inducible protein 27 & 2310061N23Rik & NM_029803 & & 3.9 \\
\hline Interferon induced transmembrane protein 2 & Ifitm2 & NM_030694.1 & -2.0 & \\
\hline Interferon induced transmembrane protein 6 & Ifitm6 & XM_133956.3 & -5.0 & \\
\hline Kruppel-like factor 6 & Copeb & NM_011803.1 & & 2.5 \\
\hline Lipocalin 2 & Len2 & NM_008491.1 & -5.1 & \\
\hline LPS-induced TN factor & Litaf & NM_019980 & & 2.6 \\
\hline Lymphocyte antigen 96 & Ly96 & NM_016923.1 & -2.2 & \\
\hline Lysozyme & Lyzs & NM_017372 & 2.5 & \\
\hline Mannose receptor, C type 1 & Mrcl & NM_008625.1 & -7.6 & \\
\hline Membrane-associated ring finger (C3HC4) 8 & Mir & NM_027920.3 & -2.2 & \\
\hline Myeloperoxidase & Mpo & NM_010824.1 & -3.3 & \\
\hline Peptidoglycan recognition protein 1 & Pglyrp1 & NM_009402.1 & -2.5 & \\
\hline Peripheral myelin protein & Pmp22 & NM_008885.1 & 3.5 & \\
\hline Peroxidasin homolog (Drosophila) & 2310075M15Rik & XM_283052 & 2.0 & \\
\hline Peroxiredoxin 2 & $\operatorname{Prd} \times 2$ & NM_011563.2 & -3.5 & \\
\hline Peroxiredoxin 5 & $\operatorname{Prd} \times 5$ & NM_012021 & & 2.4 \\
\hline Phytoceramidase, alkaline & Phca & NM_025408.1 & -2.1 & \\
\hline Prosaposin & Psap & NM_011179 & -2.1 & 2.3 \\
\hline Regulator of G-protein signaling 1 & Rgs1 & NM_016846.2 & & 4.8 \\
\hline S100 calcium binding protein A4 & $5100 a 4$ & NM_011311.1 & & 4.6 \\
\hline
\end{tabular}


Table 1 Differentially expressed host genes which mapped to immune related responses (Continued)

\begin{tabular}{|c|c|c|c|c|}
\hline S100 calcium binding protein A8 (calgranulin A) & $5100 a 8$ & NM_013650.1 & -4.4 & \\
\hline SAM domain and HD domain, 1 & Samhd1 & $\mathrm{BC} 067198$ & & 2.8 \\
\hline Selenoprotein P, plasma, 1 & Sepp 1 & NM_009155.3 & -2.4 & \\
\hline Serum amyloid A 3 & Saa3 & NM_011315 & 4.5 & \\
\hline $\begin{array}{l}\text { Solute carrier family } 11 \text { (proton-coupled divalent metal ion transporters), } \\
\text { member } 1\end{array}$ & Slc11ar & NM_013612.1 & -2.2 & \\
\hline Superoxide dismutase 2, mitochondrial & Sod2 & NM_013671.2 & & 2.9 \\
\hline Surfactant associated protein A1 & Sftpal & NM_023134.3 & 2.5 & \\
\hline Surfactant associated protein D & Sftpd & NM_009160.1 & 10.4 & \\
\hline \multicolumn{5}{|l|}{ XII Genes mentioned in text but not categorized by Panther } \\
\hline Chemokine (C-X-C motif) ligand 12 & Cxcl12 & NM_013655.2 & 4.0 & \\
\hline Chemokine (C-X-C motif) ligand 13 & Cxcl13 & NM_018866.1 & 2.1 & \\
\hline Chemokine (C-X-C motif) ligand 16 & Cxcl16 & NM_023158 & & 4.1 \\
\hline Expressed sequence AA467197 & AA467197 & NM_001004174.1 & & 8.8 \\
\hline Lymphocyte antigen 6 complex, locus A & Ly6a & NM_010738.2 & 5.8 & 4.7 \\
\hline Immunity-related GTPase family, M & $\operatorname{lrgm}$ & NM_008326.1 & & 2.8 \\
\hline Lymphocyte antigen 6 complex, locus $C$ & Lyбc & NM_010741 & & 3.0 \\
\hline Mus musculus lactotransferrin & Ltf & NM_08522.2 & -16.8 & \\
\hline Proteasome (prosome, macropain) subunit, beta type 9 & Psmb9 & NM_013585.1 & & 2.9 \\
\hline Proteasome (prosome, macropain) subunit, beta type 8 & Psmb8 & NM_010724 & & 3.2 \\
\hline Proteasome (prosome, macropain) subunit, beta type 10 & Psmb10 & NM_013640.1 & & 2.4 \\
\hline Serine (or cysteine) peptidase inhibitor, clade A, member $3 \mathrm{G}$ & Serpina3g & NM_009251.1 & & 14.8 \\
\hline Three prime repair exonuclease 1 & Trex1 & NM_011637.4 & & 2.0 \\
\hline Tryptophanyl-tRNA synthetase & Wars & NM_011710.2 & & 2.2 \\
\hline Tumor necrosis factor (ligand) superfamily, member 13b & Tnfsf13b & NM_033622 & 3.1 & 3.0 \\
\hline Ubiquitin D (Ubd) & Ubd & NM_023137.2 & & 4.2 \\
\hline Ubiquitin specific peptidase 18 & Usp18 & NM_011909.1 & & 2.6 \\
\hline
\end{tabular}

Expression was analyzed using Genome Studio and classified by immune function through Panther Immune Processes. Genes not classified by Panther but clearly related to immune processes were added manually (section XII). All processes were analyzed statistically with a $\mathrm{p}$-value $\leq 0.05$.

i.d. immunized mice at 3 weeks post-immunization confirmed increased production of CCL2, CCL3, CCL4, CCL5, CXCL9 and CXCL16 (Table 2).

Compared to lung i.d. cells, lung i.n. CD8 T cells exhibited a strong anti-viral response, displaying higher levels of interferon-stimulated genes such as Stat1, Oasl2, Gbp1 and Gbp2. Pdcd1lg, Ifit130, Wars (tryptophanyl-tRNA synthetase) and diverse MHC Class II genes, indicating sustained activation of the IFN $\gamma$ pathway. Additionally, high levels of activation markers such as $L y 6 a, L y 6 c$ and Ctla-4, together with the antigen processing protease cathepsin S (Ctss), implied that there was a larger proportion of highly differentiated effector or memory CD8 $\mathrm{T}$ cells in the lung i.n. samples [22]. Increased expression of Ly6A on lung i.n. CD8 T cells was confirmed by flow cytometry (Figure $4 \mathrm{C}$ ).

Serine peptidase inhibitor clade A member 3G, also known as Serpina3g or Spi2A exhibited the highest (14- fold) difference in expression in lung i.n. compared to lung i.d. samples. Serpina3g is highly expressed in effector and memory CD8 T cell populations [23]. During the contraction phase of immune responses, it protects expanded antigen-specific CD8 effectors from programmed cell death by inactivating lysosomal proteases [24], thereby regulating the contraction phase and ensuring that a high frequency of antigen-specific $\mathrm{T}$ cells remain to develop into memory cells [23]. The detection of high levels of Serpina3g transcript in lung i.n. samples suggests the presence of a pool of effector or memory $\mathrm{T}$ cells substantially larger than in the lung i.d. group, as confirmed by the frequency of antigen-specific cells (Figure 1).

Intriguingly, several inhibitory and activating molecules were also highly expressed in the lung i.n. samples, notably Klrc1 which is also known as NKG2A. NKG2A expression has been proposed as a marker for proliferative potential of CD8 memory $\mathrm{T}$ cells and may down- 


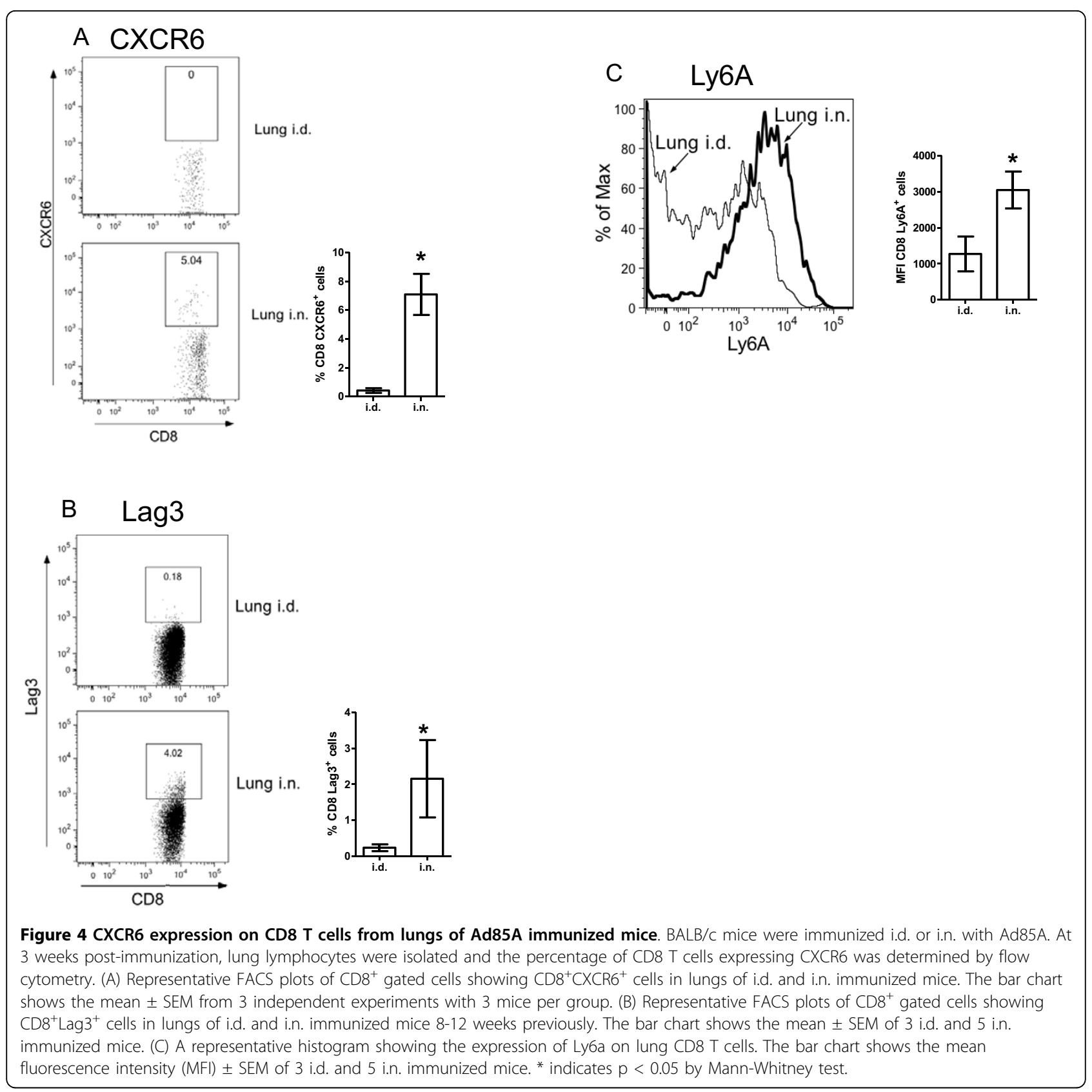

regulate effector activity as a means to limit immunopathology $[25,26]$. Interestingly another gene showing a high fold difference between lung i.n. and lung i.d. samples is $A A 467197$ (Nmes1), which was recently reported to encode a microRNA and may act to dampen down excessive inflammation [27]. In contrast Klrk1 has been reported to function as a co-stimulatory receptor for activated CD8 T cells $[28,29]$. Along with Serpina3g, these genes share important roles in regulating CD8 effector function and survival.

Several MHC class II molecules showed higher expression in the lung i.n. samples. As it has been previously reported that surface expression of Class II is not detectable on mouse $\mathrm{T}$ cells [30], a possible explanation for the presence of the transcripts could be co-purification of CD8+ dendritic cells or expression of Class II on contaminating non- $\mathrm{T}$ cells. However, microarray datasets of mature and activated murine C57BL/6 CD8 T cells http://refdic.rcai.riken.jp/welcome.cgi, isolated to $99 \%$ purity by cell sorting, also show up-regulation of MHC Class II transcripts, suggesting that murine CD8 T cells can express MHC Class II mRNA.

In summary, the comparison of lung i.n. and lung i.d. samples demonstrated a striking relative increase in 
Table 2 Production of chemokines by lung lymphocytes ex vivo after immunization with Ad85A i.d. or i.n.

\begin{tabular}{ccc}
\hline & \multicolumn{2}{c}{ Absorbance at 450nm ( \pm SD) } \\
\hline Chemokine & i.d. & i.n. \\
\hline$C C L 2$ & $0.89( \pm 0.427)$ & $1.368( \pm 0.131)$ \\
\hline$C C L 3$ & $0.334( \pm 0.066)$ & $0.745( \pm 0.008)$ \\
\hline$C C L 4$ & $0.278( \pm 0.011)$ & $0.760( \pm 0.028)$ \\
\hline$C C L 5$ & $0.386( \pm 0.098)$ & $1.470( \pm 0.211)$ \\
\hline CXCL9 & $0.259( \pm 0.059)$ & $0.566( \pm 0.034)$ \\
\hline \multicolumn{2}{c}{ Conc $(\mathrm{pg} / \mathrm{ml})$} \\
\hline CXCL16 & $3.34( \pm 0.339)$ & $6.095( \pm 0.977)$ \\
\hline
\end{tabular}

Lung lymphocytes were isolated from mice immunized 3 weeks previously and cultured in RPMI+10\% FCS for 6 hours at $37^{\circ} \mathrm{C}$ without antigen stimulation. The supernatants were assayed by ELISA for the indicated chemokines. The table shows the mean absorbance at $450 \mathrm{~nm}( \pm$ standard deviation (SD)) of 6 mice per group. For CXCL16, the mean concentration of $\mathrm{CXCL} 16(\mathrm{pg} / \mathrm{ml}, \pm \mathrm{SD})$ of 6 mice per group is shown.

expression of chemokine genes involved in migration and retention of cells as well as in genes related to activation, regulation and survival of memory $\mathrm{T}$ cells.

\section{Comparison of gene expression between spleen i.n. and spleen i.d}

As very few genes showed differential expression when spleen i.n. and i.d. samples were compared, we analyzed genes exhibiting fold differences $\geq 1.5$ (Additional file 3 ). Even so, only 9 genes were differentially expressed and fold differences between only 1.5 and 2.8 were observed. Eight of the transcripts, Klrc1, Gzmk (granzyme K), Ltf, Amy2, 111001Rik, S100a6, Kcnk5 (potassium channel subfamily k, member 5) and Klrk1 (killer cell lectin-like receptor, subfamily $\mathrm{K}$, member 1 ) were higher in spleen i.d. samples, while the single transcript more highly expressed in spleen i.n. was IGKV1-88_AJ231206_Ig_kappa_variable_1-88_289, possibly an IgG kappa chain. Higher levels of transcripts of granzyme K, killer cell activators $K l r c 1, K l r k 1$, and the inflammation marker S100a6 suggested that spleen i.d. were more activated than spleen i.n. CD8 T cells. The few differences in gene expression between the splenic i.n. and i.d. samples may be because the antigen $85 \mathrm{~A}$-specific cells in the spleen represent a small proportion of the whole splenic CD8 population (Figure 1) or because the spleen, as a major hub of lymphoid traffic, may reflect irrelevant ongoing systemic immune responses at the time of sampling.

\section{Gene expression profile in the lungs after Ad85A i.n. immunization is distinct from common lung or $M$. tuberculosis responses}

A common cluster of genes have been identified in mice and macaques as being non-specifically up-regulated during acute lung inflammation, irrespective of the type of stimulus. We compared the profile of differentially expressed genes between lung i.n. and lung i.d. samples with the genes which are subject to common upregulation following a variety of inflammatory stimuli [31]. Of the 23 genes identified as most highly and commonly expressed following exposure to a range of pathogens and environmental insults, only 5 were shared with our lung i. n./lung i.d. differentially expressed gene set (Figure 5). These were Ccl2, Ccl4, Ccl7, Cxcl9 and Gbp2. A wider group of 50 genes is induced in response to pulmonary viral or bacterial infections [31]. Prominent among these are interferon-stimulated genes that are also more highly expressed in lung i.n. than lung i.d. samples, namely, Aif1, Casp1, Ccl5, Ifit2, Ly6c, Psmb10, Psmb9, Psmb8, Stat1, Trex1, Ubd, Usp 18 and Wars. While the common responses described were measured during the acute phase of infection, less than 8 days post-exposure, i.n. administration of Ad85A induces expression of a subset of these acute-phase inflammatory molecules three weeks post-immunization, indicating that the expression profile induced may be a unique host response to Ad85A i.n. immunization.

Unsurprisingly, immunization with Ad85A induced an expression profile which was quite dissimilar to profiles generated during aerosol infection with $M$. tuberculosis or after immunization with BCG. Genes characteristically induced by mycobacteria, such as $T l r 2 / 4$ and Indo (IDO) [32], were not highly expressed in lung i.n. samples. However IFN-signalling pathway genes, such as Icsbp1 and Stat1, as well as genes associated with antiviral responses, such as Oasl2, Gbp1 and Gbp2, were strongly induced in lung i.n. samples, suggesting that virus was still present in the lungs at 3 weeks post-immunisation $[5,7]$. In spite of the differences in gene expression between mycobacterial and adenoviral immunization, several genes reported to be involved in M. tuberculosis clearance, including IFN $\gamma$ and its receptor, Il18, Cxcl13, Cxcl16, Cxcr6 and Serpina3g are induced by lung i.n. immunization $[32,33]$. Thus the immune response to antigen 85A induced by i.n. immunization with Ad85A may be favourable for protection against subsequent pulmonary challenge with $M$. tuberculosis.

\section{Discussion}

It is striking that the route of immunization with the Ad85A M. tuberculosis subunit vaccine is critical for protection against pulmonary $M$. tuberculosis challenge. Unlike conventional models of $M$. tuberculosis immunity, protection induced by Ad85A i.n. immunization in $\mathrm{BALB} / \mathrm{c}$ mice is mediated by antigen-specific CD8 T cells in the lungs with a minimal contribution from CD4 $\mathrm{T}$ cells $[7,13]$. The antigen $85 \mathrm{~A}$-specific lung CD8 cells are maintained in a highly activated state by the continued presence of antigen [5] and are not dependent on 


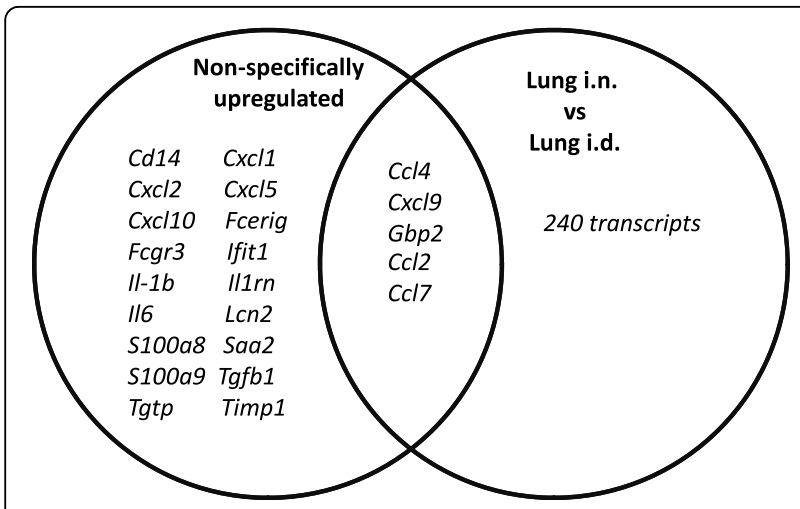

Figure 5 The overlap of genes differentially expressed between lung i.n. and lung i.d., with genes reported to be related to a common lung inflammatory response. Venn diagram showing the overlap between genes more highly expressed by lung i.n. than i.d. cells, with genes reported as upregulated in lung inflammation [31].

recruitment from the periphery [7]. These cells inhibit $M$. tuberculosis growth early after pulmonary challenge [5]. In contrast, although mice immunized i.d. with Ad85A make a strong systemic CD8 response they are not protected against $M$. tuberculosis. Nonetheless splenic immune cells have been shown capable of inhibiting $M$. tuberculosis growth when transferred into the lungs [6]. These findings prompted us to determine whether differences in gene expression, determined by microarray analysis, might provide further insight into the protective mechanisms of lung and splenic CD8 T cells.

Comparison of lung i.n. versus spleen i.d. gene expression does not show a significant difference in the expression of Ifng or Tnf or other effector molecules, suggesting that lung and splenic CD8 T cells have equal potential to inhibit $M$. tuberculosis growth, as has been demonstrated by intra-tracheal transfer of splenic lymphocytes [6]. However, lung i.n. cells expressed higher levels of chemokines such as Ccl1, Ccl2, Ccl7, Ccl8, Ccl12 and Xcl1 and Cxcl12, suggesting that the main difference between the two populations is the presence of chemokines that enhance trafficking and retention of leukocytes in the lung. When lung i.n. and lung i.d. samples were compared, several additional chemokines were more highly expressed in lung i.n. samples, namely Ccl3, Ccl4, Ccl5, Cxcl9 and Cxcl16. Strikingly the only cognate chemokine receptor more highly expressed on lung i.n. than lung i.d. CD8 T cells is Cxcr6, the receptor for Cxcl16. Cxcr6 has been proposed to be a marker for retained lung $\mathrm{T}$ cells [34]. The presence of CXCR6 protein on a proportion of lung i.n. CD8 T cells was confirmed by flow cytometry (Figure 4).

Banchereau et al. reported that upon viral infection of humans, different subsets of chemokines are secreted in a temporally regulated manner, with $C X C L 1, C X C L 2$,
CXCL3 and CXCL16 being secreted first to allow homing of naïve T cells, then CCL3, CCL4, CCL5, CXCL8, CXCL9, CXCL10 and CXCL11 to sustain localization of activated T cells, and finally CCL19, CCL22 and CXCL13 [35]. In our model, some chemokines reported to be part of the " $1^{\text {st }}$ and $2^{\text {nd }}$ waves" of chemokine expression by DC cells, specifically Xcl1, Cxcl9, Cxcl16, Ccl1, Ccl2, Ccl3, Ccl4, Ccl5, Ccl7 and Ccl8 are expressed at increased levels in lung i.n. samples at 3 weeks postinfection. A possible explanation for the presence of transcripts involved in activation and recruitment of $\mathrm{T}$ cells at this late time point in lung i.n. and not lung i.d. samples is the persistence of Ad85A in the lung [5] inducing sustained expression of IFN $\gamma$ and STAT1 which are able to coordinate expression of numerous members of the chemokine family [36]. Additionally, synergism between IFN $\gamma$ and TNF, which are produced by $85 \mathrm{~A}$-specific $\mathrm{T}$ cells (Figure 1 ), may lead to upregulation of a further subset of genes involved in $\mathrm{T}$ cell activation and recruitment, including Irg1, MHC Class II molecules and the chemokine genes including Cxcl9 [37]. Sustained expression of these chemokines may recruit and retain CD8 $\mathrm{T}$ cells in the lung so that they are able to control M. tuberculosis as soon as the mycobacteria are present in the lung [5]. In addition, these chemokines may also recruit other activated immune cells to the lung, such as macrophages, neutrophils and NK cells, ensuring that they are present in situ at the time of infection. Since a hallmark of $M$. tuberculosis infection is the very slow initiation of immune responses and delayed migration of $\mathrm{T}$ cells to the lung $[38,39]$, retention of immune $\mathrm{T}$ cells in the lungs, as induced by persistent antigen stimulation and consequent chemokine production, may be an important reason for the efficacy of i.n. immunization with Ad85A [5,38,40,41].

\section{Conclusions}

Our microarray analysis represents the first ex vivo study comparing gene expression profiles of CD8 T cells isolated from distinct sites after immunization with an adenoviral vector by different routes. It confirms earlier phenotypic data indicating that lung i.n. cells are more activated [5] than lung i.d. CD8 T cells. Thus it appears that the state of activation of the lung i.n. CD8 T cells is critical for their ability to inhibit M. tuberculosis growth early after infection. Lung i.n. cells also highly express many chemokines as well as the CXCR6 receptor. We suggest that continued expression of these molecules, as a consequence of the persistence of antigen $85 \mathrm{~A}$, helps to retain the cells in the lungs. These two properties may explain why this immunization regime is effective. An intriguing question for the future is whether the presence of a population of highly activated CD8 $\mathrm{T}$ cells in the lungs is hazardous for the 
host. However, lung i.n. samples co-express both genes activating and regulating inflammation, suggesting that the lungs may be in a stable well-balanced state.

\section{Additional material}

\section{Additional file 1: List of 550 transcripts differentially expressed} between lung i.n. and spleen i.d.

Additional file 2: List of $\mathbf{2 4 5}$ transcripts differentially expressed between lung i.n. and lung i.d.

Additional file 3: List of 9 transcripts differentially expressed between spleen i.n. and spleen i.d.

\section{Acknowledgements}

This study was supported by grant No: G0701235 from the UK Medical Research Council.

\section{Author details}

'Nuffield Department of Medicine, University of Oxford, The Peter Medawar Building for Pathogen Research, South Parks Road, Oxford OX1 3SY, UK. ${ }^{2}$ The Wellcome Trust Centre for Human Genetics, University of Oxford, Roosevelt Drive, Oxford OX3 7BN, UK.

\section{Authors' contributions}

LNL performed the RNA isolation experiments, data analysis of the microarray results and drafted the paper; DB performed the microarray analysis and statistical analysis of the data; EZT and EOR performed the intracellular cytokine analysis and $M$. tuberculosis challenge studies; JR directed the microarray studies; EZT and PCLB conceived the study design, directed the data analysis and drafted the manuscript. All authors read and approved the final manuscript.

\section{Competing interests}

The authors declare that they have no competing interests.

Received: 28 May 2010 Accepted: 13 October 2010

Published: 13 October 2010

\section{References}

1. Jiang JQ, He XS, Feng N, Greenberg HB: Qualitative and quantitative characteristics of rotavirus-specific CD8 T cells vary depending on the route of infection. J Virol 2008, 82(14):6812-6819.

2. Forbes EK, Sander C, Ronan EO, McShane H, Hill AV, Beverley PC, Tchilian EZ: Multifunctional, high-level cytokine-producing Th1 cells in the lung, but not spleen, correlate with protection against Mycobacterium tuberculosis aerosol challenge in mice. J Immunol 2008, 181(7):4955-4964.

3. Wang J, Thorson L, Stokes RW, Santosuosso M, Huygen K, Zganiacz A, Hitt $M$, Xing Z: Single mucosal, but not parenteral, immunization with recombinant adenoviral-based vaccine provides potent protection from pulmonary tuberculosis. J Immunol 2004, 173(10):6357-6365.

4. Liu L, Zhong Q, Tian T, Dubin K, Athale SK, Kupper TS: Epidermal injury and infection during poxvirus immunization is crucial for the generation of highly protective T cell-mediated immunity. Nat Med 2010, 16(2):224-227.

5. Ronan EO, Lee LN, Beverley PC, Tchilian EZ: Immunization of mice with a recombinant adenovirus vaccine inhibits the early growth of Mycobacterium tuberculosis after infection. PLoS One 2009, 4(12):e8235.

6. Santosuosso M, Zhang X, McCormick S, Wang J, Hitt M, Xing Z: Mechanisms of mucosal and parenteral tuberculosis vaccinations: adenoviral-based mucosal immunization preferentially elicits sustained accumulation of immune protective CD4 and CD8 T cells within the airway lumen. J Immunol 2005, 174(12):7986-7994.

7. Jeyanathan M, Mu J, McCormick S, Damjanovic D, Small CL, Shaler CR, Kugathasan K, Xing Z: Murine Airway Luminal Anti-tuberculosis Memory CD8 T Cells by Mucosal Immunization are Maintained Via Antigen-driven in situ Proliferation, Independent of Peripheral T Cell Recruitment. Am J Respir Crit Care Med 2010, 181(8):862-72.

8. Xing Z: Importance of T-cell location rekindled: implication for tuberculosis vaccination strategies. Expert Rev Vaccines 2009, 8(11):1465-1468

9. Huang da W, Sherman BT, Lempicki RA: Systematic and integrative analysis of large gene lists using DAVID bioinformatics resources. Nat Protoc 2009, 4(1):44-57.

10. Mi H, Thomas P: PANTHER pathway: an ontology-based pathway database coupled with data analysis tools. Methods Mol Biol 2009, 563:123-140.

11. Phillpotts RJ, Brooks TJ, Cox CS: A simple device for the exposure of animals to infectious microorganisms by the airborne route. Epidemiol Infect 1997, 118(1):71-75.

12. Santosuosso M, McCormick S, Zhang X, Zganiacz A, Xing Z: Intranasal boosting with an adenovirus-vectored vaccine markedly enhances protection by parenteral Mycobacterium bovis BCG immunization against pulmonary tuberculosis. Infect Immun 2006, 74(8):4634-4643.

13. Santosuosso M, McCormick S, Roediger E, Zhang X, Zganiacz A, Lichty BD, Xing Z: Mucosal luminal manipulation of $T$ cell geography switches on protective efficacy by otherwise ineffective parenteral genetic immunization. J Immunol 2007, 178(4):2387-2395.

14. Gordon YJ, Huang LC, Romanowski EG, Yates KA, Proske RJ, McDermott AM Human cathelicidin (LL-37), a multifunctional peptide, is expressed by ocular surface epithelia and has potent antibacterial and antiviral activity. Curr Eye Res 2005, 30(5):385-394.

15. Adams WC, Bond E, Havenga MJ, Holterman L, Goudsmit J, Karlsson Hedestam GB, Koup RA, Lore K: Adenovirus serotype 5 infects human dendritic cells via a coxsackievirus-adenovirus receptor-independent receptor pathway mediated by lactoferrin and DC-SIGN. J Gen Virol 2009, 90(Pt 7):1600-1610.

16. Lai Kwan Lam Q, King Hung Ko O, Zheng BJ, Lu L: Local BAFF gene silencing suppresses Th17-cell generation and ameliorates autoimmune arthritis. Proc Natl Acad Sci USA 2008, 105(39):14993-14998.

17. Singh G, Katyal SL: Clara cells and Clara cell 10 kD protein (CC10). Am J Respir Cell Mol Biol 1997, 17(2):141-143.

18. Griese M: Pulmonary surfactant in health and human lung diseases: state of the art. Eur Respir J 1999, 13(6):1455-1476.

19. Billerbeck E, Kang YH, Walker L, Lockstone H, Grafmueller S, Fleming $V$, Flint J, Willberg CB, Bengsch B, Seigel B, et al: Analysis of CD161 expression on human CD8+ $T$ cells defines a distinct functional subset with tissue-homing properties. Proc Natl Acad Sci USA 2010, 107(7):3006-3011.

20. Northfield JW, Kasprowicz V, Lucas M, Kersting N, Bengsch B, Kim A, Phillips RE, Walker BD, Thimme R, Lauer G, et al: CD161 expression on hepatitis C virus-specific CD8+ T cells suggests a distinct pathway of T cell differentiation. Hepatology 2008, 47(2):396-406.

21. Kim CH, Kunkel EJ, Boisvert J, Johnston B, Campbell JJ, Genovese MC, Greenberg HB, Butcher EC: Bonzo/CXCR6 expression defines type 1polarized T-cell subsets with extralymphoid tissue homing potential. J Clin Invest 2001, 107(5):595-601.

22. Marshall DR, Olivas E, Andreansky S, La Gruta NL, Neale GA, Gutierrez A, Wichlan DG, Wingo S, Cheng C, Doherty PC, et al: Effector CD8+ T cells recovered from an influenza pneumonia differentiate to a state of focused gene expression. Proc Natl Acad Sci USA 2005, 102(17):6074-6079.

23. Liu N, Phillips T, Zhang M, Wang Y, Opferman JT, Shah R, AshtonRickardt PG: Serine protease inhibitor $2 \mathrm{~A}$ is a protective factor for memory T cell development. Nat Immunol 2004, 5(9):919-926.

24. Liu N, Raja SM, Zazzeroni F, Metkar SS, Shah R, Zhang M, Wang Y, Bromme D, Russin WA, Lee JC, et al: NF-kappaB protects from the lysosomal pathway of cell death. Embo J 2003, 22(19):5313-5322.

25. Byers AM, Andrews NP, Lukacher AE: CD94/NKG2A expression is associated with proliferative potential of CD8 T cells during persistent polyoma virus infection. J Immunol 2006, 176(10):6121-6129.

26. Zhou J, Matsuoka M, Cantor H, Homer R, Enelow Rl: Cutting edge: engagement of NKG2A on CD8+ effector T cells limits immunopathology in influenza pneumonia. J Immunol 2008, 180(1):25-29.

27. Liu G, Friggeri A, Yang Y, Park YJ, Tsuruta Y, Abraham E: miR-147, a microRNA that is induced upon Toll-like receptor stimulation, regulates murine macrophage inflammatory responses. Proc Natl Acad Sci USA 2009, 106(37):15819-15824. 
28. Jamieson AM, Diefenbach A, McMahon CW, Xiong N, Carlyle JR, Raulet DH: The role of the NKG2D immunoreceptor in immune cell activation and natural killing. Immunity 2002, 17(1):19-29.

29. Raulet DH: Roles of the NKG2D immunoreceptor and its ligands. Nat Rev Immunol 2003, 3(10):781-790.

30. Schooten E, Klous P, van den Elsen PJ, Holling TM: Lack of MHC-II expression in activated mouse $T$ cells correlates with DNA methylation at the CIITA-PIII region. Immunogenetics 2005, 57(10):795-799.

31. Pennings $J L$, Kimman $T G$, Janssen $R$ : Identification of a common gene expression response in different lung inflammatory diseases in rodents and macaques. PLoS One 2008, 3(7):e2596.

32. Gonzalez-Juarrero M, Kingry LC, Ordway DJ, Henao-Tamayo M, Harton M, Basaraba RJ, Hanneman WH, Orme IM, Slayden RA: Immune response to Mycobacterium tuberculosis and identification of molecular markers of disease. Am J Respir Cell Mol Biol 2009, 40(4):398-409.

33. Khader SA, Rangel-Moreno J, Fountain JJ, Martino CA, Reiley WW, Pearl JE, Winslow GM, Woodland DL, Randall TD, Cooper AM: In a murine tuberculosis model, the absence of homeostatic chemokines delays granuloma formation and protective immunity. J Immunol 2009, 183(12):8004-8014.

34. Morgan AJ, Guillen C, Symon FA, Birring SS, Campbell JJ, Wardlaw AJ: CXCR6 identifies a putative population of retained human lung $T$ cells characterised by co-expression of activation markers. Immunobiology 2008, 213(7):599-608.

35. Piqueras B, Connolly J, Freitas H, Palucka AK, Banchereau J: Upon viral exposure, myeloid and plasmacytoid dendritic cells produce 3 waves of distinct chemokines to recruit immune effectors. Blood 2006, 107(7):2613-2618.

36. Fulkerson PC, Zimmermann N, Hassman LM, Finkelman FD, Rothenberg ME: Pulmonary chemokine expression is coordinately regulated by STAT1, STAT6, and IFN-gamma. J Immunol 2004, 173(12):7565-7574.

37. Degrandi D, Hoffmann R, Beuter-Gunia C, Pfeffer K: The proinflammatory cytokine-induced IRG1 protein associates with mitochondria. J Interferon Cytokine Res 2009, 29(1):55-67.

38. Winslow GM, Cooper A, Reiley W, Chatterjee M, Woodland DL: Early T-cell responses in tuberculosis immunity. Immunol Rev 2008, 225:284-299.

39. Reiley WW, Calayag MD, Wittmer ST, Huntington JL, Pearl JE, Fountain JJ, Martino CA, Roberts AD, Cooper AM, Winslow GM, et al: ESAT-6-specific CD4 T cell responses to aerosol Mycobacterium tuberculosis infection are initiated in the mediastinal lymph nodes. Proc Natl Acad Sci USA 2008, 105(31):10961-10966.

40. Cooper AM: T cells in mycobacterial infection and disease. Curr Opin Immunol 2009, 21(4):378-384.

41. Feng CG, Britton WJ, Palendira U, Groat NL, Briscoe H, Bean AG: Upregulation of VCAM-1 and differential expansion of beta integrinexpressing $T$ lymphocytes are associated with immunity to pulmonary Mycobacterium tuberculosis infection. J Immunol 2000, 164(9):4853-4860,

\section{Pre-publication history}

The pre-publication history for this paper can be accessed here: http://www.biomedcentral.com/1755-8794/3/46/prepub

doi:10.1186/1755-8794-3-46

Cite this article as: Lee et al: Chemokine gene expression in lung CD8 T cells correlates with protective immunity in mice immunized intranasally with Adenovirus-85A. BMC Medical Genomics 2010 3:46.

\section{Submit your next manuscript to BioMed Central and take full advantage of:}

- Convenient online submission

- Thorough peer review

- No space constraints or color figure charges

- Immediate publication on acceptance

- Inclusion in PubMed, CAS, Scopus and Google Scholar

- Research which is freely available for redistribution

Submit your manuscript at www.biomedcentral.com/submit
Biomed Central 